\title{
Integração das tecnologias digitais na UFERSA: avaliação do Ensino Remoto Emergencial na pós-graduação durante pandemia de Covid-19
}

\section{Integration of digital technologies at UFERSA: evaluation of Emergency Remote Teaching in postgraduate studies during the Covid-19 pandemic}

\author{
Jarlene Fabiana Lima de Morais ${ }^{1 *}$, Francisco Souto de Sousa Junior
}

\begin{abstract}
RESUMO
Este artigo é produto de dissertação que avaliou o Ensino Remoto Emergencial implementado na Universidade Federal Rural do Semi-Árido durante a pandemia da Covid-19, na perspectiva de alunos e professores da pós-graduação, investigando como se deu a integração das tecnologias digitais nas atividades acadêmicas no período. É um estudo de abordagem de métodos mistos (quali-quantitativo) de caráter descritivo, para o qual aplicou-se questionários com 154 discentes e 10 docentes dos cursos de pósgraduação stricto sensu. Os dados quantitativos foram avaliados por meio de análise estatística descritiva e os dados qualitativos por meio de análise de conteúdo. Os resultados evidenciaram uma boa avaliação do Ensino Remoto por parte dos discentes, tendo eles demonstrado uma boa adaptação ao ensino online e considerado as metodologias empregadas pelos docentes satisfatórias, apesar de parte dos alunos afirmarem terem tido problemas de acesso a tecnologias e a internet e adoecimento mental durante a pandemia. Já os docentes mostraram preferência pelo ensino presencial, embora não descartem a possibilidade de aderirem a atividades híbridas após a pandemia, levando em conta as oportunidades trazidas pelo Ensino Remoto.
\end{abstract}

Palavras-chave: Ensino Remoto Emergencial; Pandemia Covid-19; Tecnologias.

\begin{abstract}
This article is the result of a dissertation that evaluated the Emergency Remote Teaching implemented at the Federal University of the Semi-Arid Region during the Covid-19 pandemic, from the perspective of graduate students and professors, investigating how the integration of digital technologies in academic activities took place in this period. It is a study of a mixed methods approach (quali-quantitative) of descriptive character, for which questionnaires were applied to 154 students and 10 professors of the stricto sensu graduate courses. Quantitative data were evaluated through descriptive statistical analysis and qualitative data through content analysis. The results showed a good evaluation of Remote Teaching by the students, given that they demonstrated a good adaptation to online teaching and considered the methodologies employed by the teachers satisfactory, despite some students claim to have had problems accessing technologies and the internet and mental illness during the pandemic. Teachers, on the other hand, preferred face-to-face teaching to remote teaching, although they do not rule out the possibility of adhering to hybrid activities after the pandemic, taking into account the opportunities brought by Remote Teaching.
\end{abstract}

Keywords: Emergency Remote Teaching; Covid-19 pandemic; technologies.

\footnotetext{
${ }^{1}$ Universidade Federal Rural do Semi-Árido (UFERSA)

*jarlene.morais@ufersa.edu.br
} 


\section{INTRODUÇÃO}

Por conta das medidas sanitárias e do distanciamento social com o objetivo de conter a contaminação pela Covid-19 e óbitos dela decorrentes, um dos setores mais atingidos diretamente pela pandemia em todo o mundo foi o da educação. Fechadas, com a finalidade de reduzir o contágio pelo vírus devido à inevitável aglomeração de pessoas no ambiente escolar, as instituições de ensino precisaram repensar a educação de forma urgente.

Com as aulas presenciais suspensas desde 17 de março de 2020, pela portaria $\mathrm{n}^{\circ}$ 343 do Ministério da Educação - MEC, revogada pela portaria no 544/MEC, de 16 de junho de 2020, e com a possibilidade de continuidade das atividades remotamente, as universidades federais precisaram se adequar ao ensino remoto de forma emergencial.

No Brasil, a Lei de Diretrizes e Bases da Educação (LDB) e o Decreto $n^{\circ}$ 9.057/2017 autorizam o ensino na modalidade à distância nos ensinos médio e superior, através de convênios com instituições de ensino à distância com notório reconhecimento e credenciamento pelo Ministério da Educação. No entanto, a situação atípica e emergencial vivenciada pelas instituições de ensino, inclusive pela UFERSA, impediu que essa adequação acontecesse como recomendada e impôs a adesão a essa forma de ensino nunca antes experienciada pelos docentes e discentes dessas instituições.

Na Universidade Federal Rural do Semi-Árido - UFERSA, a portaria nº 208/2020 - GABINETE, de 17 de março de 2020, suspendeu todos os eventos e atividades presenciais na instituição, determinando o trabalho remoto enquanto durasse o estado de emergência causado pela COVID-19 para alguns grupos de servidores, mas iniciou-se um debate amplo na instituição sobre o retorno das aulas de graduação e pós-graduação no formato remoto, como implementá-lo e como avaliar essa implementação. O debate atual é sobre o retorno das aulas presenciais da graduação e pós-graduação, previstos para 2022.

Esta pesquisa objetiva verificar como se deu a integração das tecnologias digitais de informação e comunicação (TDIC) nas práticas pedagógicas da pós-graduação stricto sensu da UFERSA durante o período de Ensino Remoto Emergencial (ERE), através da avaliação que alunos e professores fazem de suas características de implementação e continuidade. A hipótese é que alguns fatores tenham exercido influência direta nas atividades remotas da pós-graduação, como acesso TDIC, problemas na interação de 
alunos e professores com essas tecnologias e/ou dificuldade de adaptação e readaptação de metodologias e estratégias pedagógicas durante o ERE.

Esse estudo fornece dados sobre o atual cenário da UFERSA acerca do uso das TDIC nas práticas pedagógicas, abre caminho para discussões sobre políticas de acesso e capacitação de profissionais e permite que sejam compreendidos os desafios enfrentados durante o ERE e o que se apresenta como possibilidade para um contexto de póspandemia.

\section{MATERIAL E MÉTODOS}

Este trabalho de pesquisa utilizou uma abordagem de métodos mistos/multimétodo (quali-quantitativo), de caráter descritivo sobre fatores que influenciaram o ensino remoto durante a pandemia na UFERSA. A abordagem de métodos mistos corresponde à "classe de pesquisa em que o pesquisador mistura ou combina técnicas, métodos, abordagens, conceitos ou linguagem da pesquisa quantitativa e qualitativa dentro de um único estudo" (JOHNSON; ONWUEBUZIE, 2004, apud PARANHOS et al., 2016, p. 391) e foi utilizada para que as informações se complementem, numa perspectiva sequencial, de acordo com Small (2011), haja vista os dados terem sido coletados de forma não simultânea, tendo a aplicação do questionário com alunos precedido a aplicação do questionário com os docentes.

O embasamento teórico para a construção do referencial bibliográfico deste trabalho foi buscado principalmente em publicações científicas dos anos 2020 e 2021, através dos descritores "ensino remoto em tempos de pandemia", "desafios do ensino remoto", "ensino superior em tempos de pandemia", "letramento digital no ensino remoto", "letramento digital no ensino superior" e "tecnologias digitais no ensino superior”. As buscas também foram realizadas em língua inglesa.

Atualmente, a UFERSA conta com 18 programas de pós-graduação stricto sensu (PPG's), sendo 3 deles em níveis de mestrado e doutorado, 14 apenas mestrado e 1 em nível de doutorado. A investigação buscou abranger todos os programas da instituição, por compreender que a temática da pesquisa importa a todos e também porque entendese que o corpo discente e docente foi igualmente impactado pelos mesmos 'problemas' e igualmente movidos pelo 'sentimento de melhor atravessar esse período de transformações. 
O projeto de pesquisa a que corresponde esse trabalho foi submetido ao Comitê de Ética em Pesquisa (CEP) e atende as normas previstas na Resolução n ${ }^{\circ}$ 510/2016 do Conselho Nacional de Saúde $(\mathrm{CNS})^{2}$. A pesquisa teve início após a devida aprovação junto ao CEP, em 28 de outubro de 2021 e foi realizada com duas populações distintas e suas respectivas amostras estão descritas a seguir:

Discentes: Para o cálculo amostral da pesquisa, foram considerados os 748 alunos ativos do semestre 2021.1 (580 mestrandos e 168 doutorandos). Assim, seria necessária uma amostra de 255 discentes a fim de que se tivesse um grau de confiança de $95 \%$ e grau de erro de $5 \%$. Os discentes foram convidados a participar da pesquisa através de email eletrônico, onde constavam as orientações, dados, objetivo da pesquisa e o link do formulário/questionário digital. $\mathrm{O}$ tipo de amostragem foi a amostragem não probabilística por conveniência, ou seja, todos os discentes de pós-graduação stricto sensu receberam o convite para responder ao questionário e aqueles que o fizeram se tornaram parte da pesquisa.

O período de coleta de respostas dos alunos foi de 28 de outubro (data em que o Comitê de Ética em Pesquisa - CEP - emitiu parecer de aprovação do Projeto) a 5 de novembro de 2021. Foi obtido um total de 154 respostas, o que representa grau de confiança de $95 \%$ e grau de erro de $7,1 \%$ e que corresponde a aproximadamente $20,5 \%$ do total de alunos ativos da pós-graduação.

Tabela 2. Perfil dos alunos respondentes

\begin{tabular}{lll}
\hline & Total & $\%$ \\
\hline Gênero & & \\
Masculino & 69 & $44,8 \%$ \\
Feminino & 84 & $54,5 \%$ \\
Outro & 1 & $0,6 \%$ \\
\hline Idade & & $44 \%$ \\
Entre 20 e 30 anos & 67 & $42 \%$ \\
Entre 30 e 40 anos & 65 & $7 \%$ \\
Entre 40 e 50 anos & 10 & $4 \%$ \\
Entre 50 e 60 anos & 6 & $3 \%$ \\
Não informaram & 5 &
\end{tabular}

Fonte: Elaboração própria

Seguindo o critério semântico. foram definidas 5 categorias de fatores a serem

\footnotetext{
${ }^{2}$ https://www.in.gov.br/materia/-/asset_publisher/Kujrw0TZC2Mb/content/id/22917581
} 
investigados através do questionário discente, a saber: a) Acesso às TDIC e à internet; b) Letramento digital; c) Práticas pedagógicas/metodológicas; d) Outros aspectos; e e) Avaliação do ERE de forma geral. A categorização, segundo Bardin (1977), é a classificação de elementos constitutivos de um conjunto com características comuns entre si.

Docentes: Para a amostragem dos docentes, foram convidados 10 (dez) docentes de programas e áreas de atuação diferentes, cujos e-mails foram encaminhados individualmente. Para estes, o critério de inclusão seria possuir orientação ativa em programa(s) de pós-graduação da UFERSA no semestre de 2021.1. A coleta de dados ocorreu no período de 10 a 20 de novembro de 2021.

Tabela 4. Perfil dos professores respondentes

\begin{tabular}{lcc}
\hline & Total & $\%$ \\
\hline Gênero & & \\
Masculino & 5 & $50 \%$ \\
Feminino & 5 & $50 \%$ \\
\hline Idade & & \\
Entre 30 e 40 anos & 3 & $30 \%$ \\
Entre 40 e 50 anos & 5 & $50 \%$ \\
Entre 50 e 60 anos & 2 & $20 \%$ \\
\hline Fonte: Elaboração própria & &
\end{tabular}

Para a coleta de dados desta pesquisa, foram utilizados: a) questionário elaborado com afirmações em escala do tipo Likert para discentes dos níveis de mestrado e doutorado da UFERSA, composto por 30 (trinta) afirmações, e b) questionário com 7 (sete) questões abertas para os docentes mais treze afirmações em escala do tipo Likert. Nesse instrumento, foram atribuídos valores entre -2 e +2 , segundo a seguinte descrição: +2 para CT (concordo totalmente), +1 para C (concordo), 0 para I (indeciso), -1 para D (discordo) e -2 para DT (discordo totalmente). Para apresentação das falas na análise qualitativa, foram atribuídos os códigos P1, P2, P3 etc, onde P significa professor.

Os dados obtidos através da escala de Likert foram tratados por meio de análise estatística descritiva, utilizando-se uma abordagem quantitativa (COSTA, 2010) estabelecendo-se média padrão e desvio padrão, com o objetivo de verificar a homogeneidade das respostas. Os dados qualitativos foram tratados por meio de análise de conteúdo, proposta por Bardin (1977), com a ajuda do software Iramuteq e seguiu as três etapas de análise propostas pela autora, a saber: pré-análise, exploração do material e tratamento dos dados. 


\section{RESULTADOS E DISCUSSÃO}

Os resultados obtidos nos questionários de pesquisa dos alunos e professores foram analisados separadamente, haja vista não terem sido aplicados simultaneamente. Assim, seus resultados serão apresentados também de forma sequencial.

Discentes: Os resultados sobre acesso às TDIC e internet mostram que, para uma parcela dos entrevistados, a disponibilidade desses recursos somou-se a outras adversidades desse período: 11,6\% dos respondentes afirmaram ter tido dificuldade de acesso a um equipamento eletrônico para continuidade das atividades acadêmicas durante a pandemia. Quando o assunto é acesso à internet, esse percentual é um pouco maior $(16,8 \%)$. A maioria dos alunos, porém, (74\%) disse não ter encontrado problemas de acesso à internet durante esse período. $\mathrm{O}$ acesso às TDIC e à internet é fator de inclusão social e não se pode permitir que essas dificuldades sejam limitadoras dentro do contexto universitário. É importante destacar que, além do acesso, a boa qualidade dos equipamentos e do serviço de internet são cruciais nesse contexto de atividades online. Nesse sentido, 20,1\% dos alunos responderam que a internet dos professores "cai” com frequência durante as aulas, percentual que sobe para 33,1\% quando a questão diz respeito à própria internet. Outra questão observada nesse trabalho é que $19 \%$ dos discentes afirmaram que precisam/precisaram dividir o equipamento utilizado para o ERE com outras pessoas da casa. Isso pode ter sido comum nos lares, uma vez que muitos tiveram que trabalhar de forma remota e crianças ficaram sem ir para a escola por um período longo.

A segunda categoria investigada no questionário aplicado com os estudantes diz respeito ao letramento digital, fundamental no uso das tecnologias de informação e comunicação (TDIC). O letramento digital é construir sentido a partir de textos que trazem palavras, imagens e sons incorporados numa mesma superfície, os chamados textos multimodais, sendo capaz de localizar, filtrar e avaliar criticamente informações disponibilizadas de forma eletrônica (CARMO, 2003) Assim, o acesso às TDIC em si não é suficiente, é preciso - e durante o ERE tornou-se essencial - que se vá além da competência técnica em relação ao uso de plataformas e dos recursos digitais, sendo necessário "organizar e orientar didaticamente o processo de ensino-aprendizagem à distância, na presença virtual constante e na habilidade para ler e escrever com fluência em ambientes digitais" (VIEIRA; SILVA, 2020, p. 1028). De forma geral, grande parte 
dos alunos fizeram uma boa avaliação de seu desempenho com as TDIC durante o ERE, bem como de seus professores: $74 \%$ dos discentes afirmaram que os recursos digitais foram bem aproveitados pelos professores e $76 \%$ avaliam as atividades pedagógicas através das tecnologias de forma positiva. Isso pode revelar o potencial que essas tecnologias representam para o ensino superior quando os professores se apropriam de suas especificidades. Essa apropriação, segundo Vidal, Mercado (2020), acontece quando o docente conhece a interface, atribui sentido ao seu uso, conhece os meios e os fins de sua utilização e que caminhos seguir para aplicar as TDIC ao conteúdo. Esse processo só acontece, segundo Riedner, Pischetola (2016), quando há uma boa formação do professor e garantias de condições pedagógicas favoráveis, pois "é o professor, com base na sua formação, que tem a possibilidade de propor mudanças metodológicas e transformar o uso de tecnologia numa prática social e cultural" (RIEDNER; PISCHETOLA, 2016, p.38). Acerca de si mesmos, embora $22 \%$ dos respondentes tenham afirmado que tiveram alguma dificuldade na utilização das plataformas de aprendizagem durante o ERE, destaca-se que $76 \%$ deles avaliaram positivamente o seu desempenho nas atividades desenvolvidas através das tecnologias digitais.

Na categoria sobre práticas pedagógicas e metodológicas, analisou-se a percepção dos alunos sobre a integração entre gestão universitária, docentes e programas no interesse e busca de melhorias para o ensino remoto e as estratégias adotadas pelos docentes em suas atividades. Nesse sentido, $21 \%$ dos alunos afirmaram concordância total e $48 \%$ concordaram com as estratégias de integração, ensino e avaliação implementados nesse período. Cabe destacar que $85 \%$ dos alunos informaram ter percebido que os docentes buscaram aprender mais sobre tecnologias. Ainda, $72 \%$ dos respondentes concordaram que as estratégias de adaptação do presencial para o remoto foram satisfatórias, assim como a maioria dos alunos concordaram que as formas de avaliação foram apropriadas para o contexto de pandemia: $81 \%$ das respostas. Essa avaliação é pertinente e significativa, haja vista que "a escolha de determinado tipo de tecnologia altera profundamente a natureza do processo educacional e a comunicação entre os participantes" (KENSKI, 2007, p. 45).

As respostas às assertivas da categoria 4 evidenciou que 49,3\% dos discentes encontraram dificuldades de auto organização durante o ERE e 63,7\% disseram dividir o horário das aulas remotas com alguma outra atividade. Isso porque o lar passou a abrigar o ambiente de trabalho, o espaço de estudo e pesquisa e, para os que têm filho(s), a escola 
destes, tudo ao mesmo tempo, no mesmo lugar. Torna-se importante destacar que o percentual de discentes que responderam positivamente à assertiva 13 é maior entre o gênero feminino: das 84 mulheres que responderam ao questionário, 67,8\% disseram dividir o horário da aula com alguma outra atividade, enquanto 57,9\% do total de homens respondentes fizeram a mesma afirmação. Destaque-se ainda que foram 70 mulheres que disseram que a sua saúde mental foi abalada durante a pandemia, o que corresponde a $83,3 \%$ do total de alunas. Os discentes homens que fizeram esta afirmação foram 46 (66,6\% dos respondentes).

A quinta e última categoria investigada com os discentes objetivou obter dos alunos de pós-graduação uma avaliação geral do ERE. Nesse sentido, 44,8\% dos discentes afirmaram ter tido algum projeto prejudicado ou paralisado durante a pandemia e $20,1 \%$ dos alunos pensaram em trancar algum semestre durante o ERE. Além disso, um percentual significativo $(43,5 \%)$ afirmou ter encontrado dificuldade de adaptação da modalidade de ensino presencial para a remota. Ainda, 51,3\% dos alunos afirmaram que as aulas remotas são mais cansativas que as presenciais, contudo, 64,9\% deles disseram que os encontros com seus orientadores foram sempre produtivos. É interessante observar também que 78,6\% dos respondentes disseram que têm participado de eventos ou cursado disciplinas de outras instituições nesse período, o que se conecta com o fato de $91,5 \%$ dos participantes da pesquisa considerarem interessante a mobilidade virtual como forma de tornar a sua formação e currículo mais ricos. Outra questão relevante a ser observada nas respostas dos discentes é que 51,9\% deles afirmaram que o ensino remoto é menos eficiente que o presencial, contudo, 76,7\% deles consideram interessante a possibilidade de atividades remotas continuarem sendo oferecidas na instituição mesmo após a pandemia. Mesmo que possa parecer, as afirmações não são antagônicas e podem refletir simplesmente a necessidade de que a instituição repense a adoção de algumas atividades remotas notadamente eficientes, o que caracterizaria uma modalidade híbrida de educação.

Docentes: Após leitura e análise das respostas obtidas no questionário aplicado com os docentes, os textos foram transcritos para o Word e salvos em documento como 'Texto sem formatação', com a codificação Unicode (UTF-8), a fim de tornar possível a leitura pelo programa Iramuteq, a partir do qual foi gerada a nuvem de palavras para demonstrar, de maneira visual, a frequência das palavras citadas pelos docentes entrevistados. Foi possível visualizar que a palavra discente encontrou-se em evidência 
em relação às demais. Também se apresentam de forma significativa os vocábulos atividade, aula, interação, seguidas ainda das palavras docente, virtual, google meet, o que significa que esses foram os termos mais citados pelos professores em suas reflexões sobre o ERE.

$\mathrm{Na}$ análise de similitude, pôde-se verificar a ligação entre as palavras do corpus textual e a proximidade entre elas, bem como inferir a estrutura de construção do texto e seus temas importantes, a partir da coocorrência entre os termos utilizados nas respostas, nesse caso, dos docentes (SALVIATI, 2017). Foi possível observar que a palavra discente surge no centro como destaque, de onde se ramificam outras que apresentam expressão considerável: interação, docente, aula, referências inerentes ao processo de implementação e continuidade do ERE. Destaque-se ainda que interação aparece ligado ao termo online; ferramenta a virtual; desafio conectada à pandemia; e aula ligada às palavras atividade e remoto.

Assim, utilizando-se o critério semântico, estabeleceram-se os seguintes índices: desafio, interação, híbrido e presencial. Os indicadores permitiram a codificação das unidades de registro que tornaram possível a descrição das características pertinentes do conteúdo e as inferências. A interpretação final dos dados gira em torno de 4 categorias: a) Desafios enfrentados no ERE; b) Dificuldade de interação com discentes e de readaptação; c) $\mathrm{O}$ ensino presencial melhor que o remoto; e d) Atividades híbridas como possibilidade.

Dos professores entrevistados, 70\% tiveram alguma pesquisa prejudicada ou modificada no período, devido ao fechamento temporário dos laboratórios, à necessidade de redução do número de alunos nesses locais, mesmo após a sua reabertura, ajuste de pesquisas de campo ao distanciamento social, à alta no preço de produtos e serviços e falta de recursos financeiros. Apenas 4 professores afirmaram que o suporte oferecido pela instituição aos docentes (treinamentos, cursos) acerca de uso das TDIC foi satisfatório. "Tivemos que aprender por instinto", disse P1. Já P5 falou que "tamanha crie (sic) merecia melhor gestão de treinamento com massivas campanhas de divulgação e sensibilização à participação", enquanto P4 questionou “qual suporte?”, dando a entender que este não existiu.

Também se constituíram desafios segundo os docentes, "a rotina doméstica dentro do trabalho" (P5), "lidar com a exposição pessoal" (P7), "a ausência de aulas práticas", e “o excesso de justificativas para todas as falhas no cumprimento dos prazos pelos 
discentes", argumentados por P8 e as "pandemias que vivemos, a Covid 19 e a pandemia de adoecimento psíquico no social" (P2). Nesse sentido, 9 dos 10 docentes afirmaram que tiveram orientando(s) que apresentaram problemas emocionais em razão da pandemia, sendo que, quando se trata de colega(s) de trabalho, esse percentual é de $100 \%$.

No entanto, a dificuldade de interação com os pós-graduandos durante a pandemia foi o maior desafio enfrentado pelos docentes. $50 \%$ deles mencionaram diretamente esse ponto em suas declarações. Cabe dizer que $69 \%$ dos alunos responderam que suas câmeras costumam estar desligadas durante as aulas remotas. Para P9, "não poder olhar para a reação dos alunos, não poder instigar uma maior participação, não saber se estão entendendo realmente" foi difícil. P1 disse que "a maior dificultade (sic) é a falta de contato com os estudantes", complementando que a interação com eles é muito baixa. P6 afirma que o aluno se mostrou cansado ao longo desse período "fazendo as aulas ficarem sem interação", enfim, a "falta de interação por parte dos discentes" (P7) se apresentou como obstáculo ao êxito de atividades propostas pelos professores da pós-graduação.

Como estratégias pedagógico-metodológicas para otimizar o desempenho dos alunos durante o ERE, os entrevistados citaram especialmente a diminuição do tempo das aulas, o incentivo à produção de material visual e a participação virtual de especialistas em determinados temas, a fim de enriquecer as aulas e provocar o intercâmbio de conhecimentos.

Ao realizarem uma breve avaliação do ERE, o conteúdo das respostas evidencia uma concordância entre os respondentes sobre o ensino presencial ser melhor, sendo que metade deles ressaltaram o ERE como uma necessidade para que se mantivesse o distanciamento necessário ao mesmo tempo em que tornou possível a manutenção das atividades de ensino e pesquisa. Silveira (2020) afirma que o ERE foi implementado sobre uma mistura de saberes acumulados, senso de urgência, muitas incertezas e grande carga de improviso. Nesse sentido, o ensino remoto foi considerado por P3 como um paliativo. Para P8, o ensino remoto "não atende a um aprendizado de qualidade" e enfatiza a sua crença que "a sala de aula presencial deve ser sempre um posto chave para a qualidade da aprendizagem". Para P5, "a falta de contato presencial foi trazendo um afastamento dos personagens" e, segundo P7, “o aprendizado ficou comprometido no ERE justamente pela "falta de interação/participação dos discentes". A análise feita por P9 diz que dependendo da matéria/conteúdo, as aulas remotas podem funcionar "de muito bem a péssimo" e observa que o ERE funciona melhor na pós-graduação do que na graduação, 
destacando ainda que houve um aumento de trabalho nesse período, tanto para o professor quanto para o aluno, de forma assíncrona.

Entretanto, é interessante observar que há entre os docentes uma concordância sobre a possibilidade de continuidade do uso das TDIC em atividades da pós-graduação em um contexto de pós-pandemia, influenciando as estratégias pedagógicas e atividades prático-teóricas de ensino. A afirmação de P3 sobre o assunto é que "boa parte das tecnologias utilizadas serão incorporadas ao cotidiano, o que pode permitir uma otimização do tempo, com maior valorização das atividades presenciais e com a extensão do uso de atividades que podem ser realizadas remotamente". Já P4 afirma que "o ensino remoto nos mostrou novas ferramentas de ensino e, principalmente, a possibilidade de interação entre instituições e profissionais distantes", o que fomenta o ensino, segundo ele.

No entanto, os docentes observam que as TDIC não devem constituir o único espaço de interação e aprendizagem no contexto acadêmico, "devendo-se ter o cuidado de respeitar os limites nesta relação de ensino-aprendizagem" (P3), "deixando a interação online para apoiar nossas ações de pesquisa, mas não como espaço tempo único no trabalho de pesquisar e transformar nossos mundos comuns" (P2) e compreendendo "que a sala de aula presencial é ainda um ponto chave para a aprendizagem e que as tecnologias são apenas estratégias de suporte (e não a base de tudo)" (P8). Torna-se importante, então, trazer para discussão as possibilidades viáveis e efetivas de uso das TDIC nas atividades acadêmicas.

De qualquer forma, o ERE acelerou discussões profundas sobre a integração das tecnologias nas instituições de ensino, trouxe questionamentos pertinentes sobre metodologias ativas de aprendizagem, capacitação docente, acesso igualitário às TDIC e à educação e também sobre a necessidade de revisão de práticas tradicionais de ensino.

O ensino híbrido vem sendo discutido há alguns anos, mesmo antes da pandemia, como a tentativa de combinar todas as vantagens da educação online com todos os benefícios da sala de aula tradicional, misturando o antigo com o novo, oferecendo melhorias em relação ao modo tradicional de ensino, mas não rompendo com ele (HORN; STAKER. 2013), combinando "momentos em que o estudante estuda em um ambiente virtual, utilizando ferramentas tradicionalmente da educação a distância, com outros em que a aprendizagem é presencial." (MACHADO; LUPEPSO; JUNGBLUTH, 2017, p. 8)

Silveira (2020) acredita que o ensino remoto parece ser a "materialização da 
aceleração do processo de transição para cenários em que o Ensino Híbrido passa a ser a realidade de fato" (SILVEIRA, 2020, p.3) e ainda um "laboratório para futuros cenários educacionais, nos quais o Ensino Híbrido desponta como uma possibilidade real, visto que a barreira da interação remota foi quebrada de maneira abrupta e acelerada. (SILVEIRA, 2020, p. 20). A gravação das aulas remotas, por exemplo, constituiu-se em um facilitador de acesso ao conteúdo para aqueles que não puderam comparecer aos encontros, bem como ferramenta de acompanhamento individual de assuntos não compreendidos durante as aulas.

Entretanto, se por um lado, alguns autores vêem no ERE a possibilidade de expansão e modernização das práticas de ensino, outros se mostram preocupados com um possível cenário de maior sucateamento das instituições de educação brasileiras. Gomes, Vasconcelos (2021), por exemplo, destacam as desigualdades socioeducacionais acentuadas durante o ERE, evidentes na disponibilidade de equipamentos por domicílio, o próprio espaço e as condições de concentração para estudos em casa. Os autores dizem que "a modernização tecnológica, compreensiva e essencial, no cenário pandêmico, apresenta suas grandezas e misérias, num mosaico onde é difícil discernir se os claros ou os escuros ocupam maior espaço.” (GOMES; VASCONCELOS, 2021, p. 190). Eles admitem que houve uma superação de lacunas caracterizadas pela resistência à mudança da aula presencial para a online e pelo incentivo a algumas estratégias pedagógicodidáticas. No entanto, declaram que, durante o ERE, predominou o uso conservador de tecnologias digitais avançadas, afirmando que "com ampla frequência a educação voltouse ao conteudismo e retornou ao conceito da sua transmissão." (GOMES; VASCONCELOS, 2021, p. 184). Santinello, Costa, Santos (2020, p. 15) alertam que "é salutar enfatizar que o uso inapropriado e mercadológico da proposta [do ensino híbrido] faz com que o processo de ensino e de aprendizagem se torne incoerente e acrítico", sem a devida reflexão, o que não gera aprendizagem.

Atualmente, é permitido que cursos presenciais de instituições de ensino superior (IES) ofertem carga horária de suas disciplinas parcial ou integralmente na modalidade de $\mathrm{EaD}$, até o limite de $40 \%$ da carga horária total do curso, conforme Portaria 2.117/2019. Para estimular a adesão das universidades federais na oferta de cursos em formato EaD, o Ministério da Educação, por meio da Secretaria de Educação Superior (Sesu), está desenvolvendo o Programa Reuni Digital, cujo documento ainda se encontra em revisão, porém já com amplos debates acerca da criação de uma universidade federal 
digital. Os críticos entendem que a proposta comprometerá ainda mais o orçamento das IES com investimentos em uma educação que parece desvinculada de um processo de implementação das TDIC, amplia a polarização de ensino presencial e à distância, a padronização e centralização proporcionados por uma rede nacional que desconsidera a diversidade e regionalidades do país (UFBA, 2021) e desvaloriza os profissionais da educação.

A tentativa de recorrer às TDIC como forma de mascarar um ensino voltado para práticas tradicionais de ensino, sistemas desiguais e excludentes de educação, falta de investimento real nas instituições não caracterizam a verdadeira integração das TDIC no contexto educacional. Para Gomes, Vasconcelos (2021, p. 192), a educação à distância "está longe de ser uma panaceia democratizante". Sobre os dispositivos que regularizam a oferta da educação à distância, os autores dizem que são

Como as águas, originam-se e correm coincidentemente na direção de menores custos educacionais, tanto para o Estado como para os provedores particulares. Portanto, a atração exercida pela "sacra" redução do déficit público, ainda mais num desprezado setor social, aliada aos incentivos dos mercados e da lucratividade, pode conduzir a uma conjugação de forças no sentido de precarizar ainda mais a educação e o cumprimento do seu direito. (GOMES; VASCONCELOS, 2021, p. 194-195).

Apesar de qualquer crítica, é inegável que as TDIC já fazem parte do contexto universitário e a pandemia da Covid-19 reforçou a necessidade de falar sobre elas, sobre acesso democrático e sobre seus impactos socioculturais na cognição e no comportamento humanos. O ERE não se constituiu em um modelo perfeito de integração de TDIC na pósgraduação da UFERSA, mas cumpriu o importante papel de manter a universidade em atividade, quebrando a barreira da resistência, evidenciando alguns problemas estruturais e expondo a importância do professor como mediador em uma rede cada dia mais povoada de falsas notícias, falsa ciência, políticas excludentes e qualidade duvidosa das informações a que se tem acesso, por serem instáveis e não controladas.

\section{CONCLUSÃO}

Diante dos dados obtidos nesta pesquisa, o que se conclui é que tanto alunos quanto professores enfrentaram desafios no ERE, seja de caráter mais instrumental, como a falta de (bons) equipamentos e internet, seja em forma de capacitação e preparo emocional para lidar com o novo cenário imposto. Esses desafios resultaram, por um lado, 
em uma avaliação da educação presencial como forma ideal de ensino e, por outro, em uma análise satisfatória do desempenho de alunos e professores durante o ERE, no que diz respeito à realização de atividades no formato não presencial, sendo cumpridos os prazos regulares do calendário acadêmico da pós-graduação. Porém, isso não quer dizer que todas as potencialidades das TDIC foram exploradas e que a sua integração no processo de ensino e aprendizagem se deu de forma plena.

Em face disso, é preciso que um modelo de educação eficaz através das TDIC seja amplamente discutido, pois a inovação na educação é urgente, mas esta não se garante apenas com a aquisição de equipamentos, e sim, com a integração desses recursos, da gestão, dos professores e dos alunos em um projeto pedagógico de capacitação contínua, de atualização, de observância às mudanças socioculturais, políticas e econômicas. A inovação na educação se dá quando há a oportunidade de intercâmbio de culturas e de ideias, com espaço para debates e para as críticas que ajudam a construir conhecimentos de forma colaborativa, a longo prazo, quando há um projeto político sério de investimento em equipamentos e capacitação, e não em atendimento a um projeto pessoal por um quadriênio. É necessário perceber, respeitar e procurar atender a essas demandas com uma política responsável de inclusão, tanto digital quanto social, haja vista que uma é consequência da outra e compreender as TDIC como ambiente de criação e articulação de novos grupos sociais, que unidos por aspirações, objetivos e preferências semelhantes, buscam espaço e direitos sociais.

Os dados da pesquisa mostraram ainda alunos e professores cansados, com sua saúde mental afetada, docentes que alegaram dificuldade de interação com discentes e falta de suporte institucional, mas que, apesar de tudo, não descartam as possibilidades que se abrem com a experiência obtida no ERE, mesmo após o contexto pandêmico vivido, como as atividades híbridas. Assim, esse parece um momento propício para se investir em TDIC para a educação, mas é preciso estar atento ao projeto de sucateamento do ensino, pois o que pode parecer investimento em recursos tecnológicos pode se revelar um ensaio para corte de gastos com profissionais e estrutura física das universidades, alargando o abismo entre a comunidade e a universidade aumentando a marginalização e a exclusão.

É relevante um estudo mais aprofundado sobre a apropriação dos espaços digitais de aprendizagem utilizados no ERE como algo que poderá significar o alicerce de uma inovação pedagógica e tecnológica significativa na universidade, com mudanças culturais 
expressivas diante das rápidas alterações sociais e dos avanços tecnológicos, por isso, é desinteressante a dicotomia entre o ensino presencial e o remoto quando se tenta obter uma universidade mais integrada, romper alguns paradigmas e acabar com a evasão em um contexto em que as TDIC despontaram como uma saída viável e eficiente para a continuidade de suas atividades.

É preciso e urgente mais investimento em tecnologias dentro das universidades, mas não apenas isso. É necessário também proporcionar a capacitação docente para o uso operacional e crítico desses recursos. As TDIC devem ser mais que recursos tecnológicos de suporte à educação, elas devem ser instrumentos de construção do pensamento crítico, compartilhamento de ideias e objetos de luta por uma educação mais livre e libertadora.

\section{REFERÊNCIAS}

BARDIN, L., Análise de conteúdo. Lisboa: Edições, 1977, p.70.

BRASIL. Ministério da Educação. Gabinete do Ministro. Portaria 2.117, de 6 de dezembro de 2019. Brasília, 2019.

. Ministério da Educação. Gabinete do Ministro. Portaria 343 de 17 de março de 2020. Brasília, 2020.

. Ministério da Educação. Gabinete do Ministro. Portaria 544, de 16 de junho de 2020. Brasília, 2020.

CARMO, Josué G. Botura. O letramento digital e a inclusão social. 2003. Disponível em: http://www.educacaoliteratura.com.br/index\%2092.htm Acesso em 20 abr. 2020

CGEE. Programa REUNI Digital - Programa de Expansão da EAD nas universidades federais. Brasília, 2021. Versão 3, de 12 de outubro de 2021.

COSTA, Sérgio Francisco. Estatística aplicada à pesquisa em educação. Brasília: Liber livro, 2010, p.91.

GOMES, C. A.; VASCONCELOS, I. C. O. A Educação Superior no labirinto da pandemia. Integración Y Conocimiento, v. 10, n. 1, p. 182-205, 2021. Disponível em: https://revistas.unc.edu.ar/index.php/integracionyconocimiento/article/view/31966 Acesso em 29 out. 2021

HORN, M. B.; STAKER, H. Ensino Híbrido: uma inovação disruptiva? Uma introdução à Teoria dos Híbridos. Christensen Institute. 2013. Disponível em: https://www.christenseninstitute.org/publications/ensino-hibrido/ Acesso em 12 mai. 2021 
KENSKI, V. M. Educação e Tecnologias: o novo ritmo da informação. Campinas, SP. Editora Papirus, 2007. $2^{\mathrm{a}}$ Ed.

MACHADO, N. S.; LUPEPSO, M.; JUNGBLUTH, A. Educação Híbrida. UFPR, 2017. Disponível em

http://cipead.ufpr.br/portal1/materiais/ufpr_hibrida/livro_educacao_hibrida.pdf Acesso em 11 mai. 2021.

Lei no 9.394. Lei de Diretrizes e Bases da Educação Nacional (LDB), de 20 de dezembro de 1996. Disponível em http://www.planalto.gov.br/ccivil_03/Leis/L9394.htm

PARANHOS, Ranulfo et al. Uma introdução aos métodos mistos. Sociologias, Porto Alegre, ano 18, no 42, mai/ago 2016, p. 384-411. Disponível em:

https://www.scielo.br/j/soc/a/WtDMmCV3jQB8mT6tmpnzkKc/\# Acesso em 8 jan. 2022

RIEDNER, D. D. T.; PISCHETOLA, M. Tecnologias Digitais no Ensino Superior: uma possibilidade de inovação das práticas? EFT: Educação, Formação \& Tecnologias, v. 9, n. 2, p. 37-55, 2016. Disponível em:

https://dialnet.unirioja.es/servlet/articulo?codigo=6119342 Acesso em 18 set. 2021

SALVIATI, M. E. Manual do Aplicativo Iramuteq (versão 0.7 Alpha 2 e R Versão 3.2.3). Planaltina, março de 2017. Disponível em:

http://www.iramuteq.org/documentation/fichiers/manual-do-aplicativo-iramuteq-parmaria-elisabeth-salviati Acesso em 29 nov. 2021

SANTINELLO, J.; COSTA, M. L. F.; SANTOS, R. O. dos. A virtualização do Ensino Superior: reflexões sobre políticas públicas e Educação Híbrida. Educar em Revista. Curitiba, v. 36, e76042, 2020. Disponível em http://www.scielo.br/scielo.php?script=sci_arttext\&pid=S010440602020000100603\&lng=en\&nrm=iso . Acesso em 11 mai. 2021. Epub Dec 21, 2020 .

SILVEIRA, Ismar Frango. O Papel da Aprendizagem Ativa no Ensino Híbrido em um Mundo Pós Pandemia: reflexões e perspectivas. Revista Brasileira de Aprendizagem Aberta e a Distância, v. 2, p. 1-27, 2020. Disponível em:

http://seer.abed.net.br/index.php/RBAAD/article/view/557 Acesso em 30 out. 2021. DOI: https://doi.org/10.17143/rbaad.v2iEspecial.557

SMALL, M. L. How to conduct a mixed methods study: Recent trends in rapidly growing literature. Annual Review Sociology, 37:57-86, 2011. Disponível em: https://www.annualreviews.org/doi/pdf/10.1146/annurev.soc.012809.102657\#articledenial Acesso em 8 jan. 2022

UNIVERSIDADE FEDERAL DA BAHIA. Nota Técnica SEAD/UFBA nº $01-2021$. Uma análise sobre o programa REUNI DIGITAL, proposto pelo MEC. Salvador, 2021. Disponível em: https://drive.google.com/file/d/1PH3290iMzHAOe81ZEe5HyLXHSvoKbssg/view Acesso em 2 nov. 2021 
UNIVERSIDADE FEDERAL RURAL DO SEMI-ÁRIDO. Portaria UFERSA/GAB n ${ }^{\circ}$ 208/2020, de 17 de março de 2020. Mossoró, 2020. Disponível em https://documentos.ufersa.edu.br/wp-content/uploads/sites/79/2020/03/Portarian\%C2\%BA-208-de-17-de-mar\%C3\%A7o-de-2020.pdf

VIDAL, O. F.; MERCADO, L. P. L. Integração das tecnologias digitais da informação e comunicação em práticas pedagógicas inovadoras no ensino superior. Revista Diálogo Educacional, v. 20, n. 65, p. 722-749, abr./jun. 2020. Disponível em https://periodicos.pucpr.br/index.php/dialogoeducacional/article/view/26157. Acesso em 4 set. 2021

VIEIRA, Márcia de Freitas; SILVA, Carlos Manuel Seco da. A Educação no contexto da pandemia de COVID-19: uma revisão sistemática de literatura. Revista Brasileira de Informática na Educação, [S.1.], v. 28, p. 1013-1031, dez. 2020. ISSN 2317-6121. Disponível em: https://br-ie.org/pub/index.php/rbie/article/view/v28p1013. Acesso em: 15 set. 2021. doi:http://dx.doi.org/10.5753/rbie.2020.28.0.1013 